\title{
Effect of Co-Axial Flow Velocity on Soot Formation in a Laminar Jet Diffusion Flame under Microgravity*
}

\author{
Byoung-Ho JEON ${ }^{* *}$, Osamu FUJITA ${ }^{* *}$, Yuji NAKAMURA ${ }^{* *}$ and Hiroyuki ITO ** \\ ** Division of Mechanical and Space Engineering, Hokkaido University, \\ N13 W8 Kita-ku, Sapporo 060-8628, Japan \\ E-mail: ofujita@eng.hokudai.ac.jp
}

\begin{abstract}
To examine the effect of low co-axial flow on soot formation in a laminar jet diffusion flame, microgravity experiments have been conducted. The tested co-axial flow velocity range is $0-7.3 \mathrm{~cm} / \mathrm{s}$, which is very difficult to provide on the ground because of suffering from the additional external flow induced by buoyancy force. The result showed that the soot formation characteristics were greatly affected by co-axial flow velocity at the low flow velocity range, that is, soot concentration increased with increase in the external flow velocity. According to the radial distributions, the effect of external flow velocity on the soot formation was prominent near the outer edge of visible flame. A comparison with numerical calculation suggested that the increase of soot concentration was caused by increased flame temperature in the area of low oxygen and fuel excess region.
\end{abstract}

Key words: Combustion, Soot, Co-Flow, Microgravity, Jet Diffusion Flame

\section{Introduction}

Soot formation mechanism is one of the most important subjects in combustion researches, for instance, from the view of Diesel engine emission, radiative heat transfer efficiency in combustion furnaces, and so on. Regarding fire accident, radiation characteristics of flame in a low external flow velocity are very important because it strongly affects the fire propagation processes. Further, in the situation of fire accident, air flow velocity near the flame changes depending on the size of the flame itself, dimension of the surrounding space, and presence of air passage in the burning compartment. Since radiation characteristics of the flame are directly related with soot concentration, it is essential to investigate the effect of external air flow on soot formation as a fundamental data to understand fire propagation processes. Nevertheless, there is limited knowledge about the effect of external flow on soot formation, especially for low external flow velocity range, which more likely appears in a fire system. One of the reasons why the data is so limited is because of the difficulty to set the surrounding flow velocity precisely, especially in low flow velocity range because of the presence of uncontrollable disturbance induced by buoyancy force. In the present work, therefore, microgravity experiments, which are free from buoyancy driven flow, are introduced to attain well defined co-axial flow field even with flame and the attempt to determine soot formation characteristics as a function of external flow velocity is made, especially for very low flow velocity range.

To date, extensive researches on soot formation have been conducted in a variety of conditions, including microgravity $[1,2]$. Bahadori et al. attempted to understand the effect

${ }^{*}$ Received 7 Sep., 2007 (No. 07-0520) [DOI: 10.1299/jtst.2.281] 
of gravity on soot formation by both experimental and theoretical means $[3,4]$. However, they only observed the soot formation in still air with and without gravity. Faeth and co-workers also studied the effect of buoyancy on the structure of a diffusion flame and the properties of soot in the flame by experimental and numerical approaches $[5,6]$. They further examined the effect of fuel injection velocity to know the change of sooting area in the flame as well as shape of visible flame [7,8], while they made experiments in quiescent atmosphere and did not change the external flow velocity. Lin et al. have attempted to investigate the effect of flow velocity ratio of fuel injection and external flow under reduced buoyancy force condition. For this purpose they have made experiments in reduced pressure [9-12]. Although their trial was effective to reduce the buoyancy-induced disturbance, pressure itself affected the soot formation characteristics $[13,14]$.

Walsh et al. has studied the soot formation in a diffusion flame with co-axial flow in reduced gravity via parabolic flight tests. However, they only examined constant external flow velocity of $35 \mathrm{~cm} / \mathrm{s}$, and investigated the effect of fuel dilution with inert gas on soot concentration, flame temperature, and other chemical structures [15]. To date, the research on the soot formation in very low external flow, such less than $10 \mathrm{~cm} / \mathrm{s}$ attainable only in high quality microgravity environment, is hardly found in the previous references $[6,16]$. In the present work, therefore, the authors have attempted to investigate the dependency of soot formation characteristics on low external flow velocity by utilizing microgravity environment.

\section{Experimental}

All experiments were carried out in a 50m drop tower located in Akabira, Hokkaido, Japan [17]. Figure 1 shows the experimental setup installed in the drop capsule.

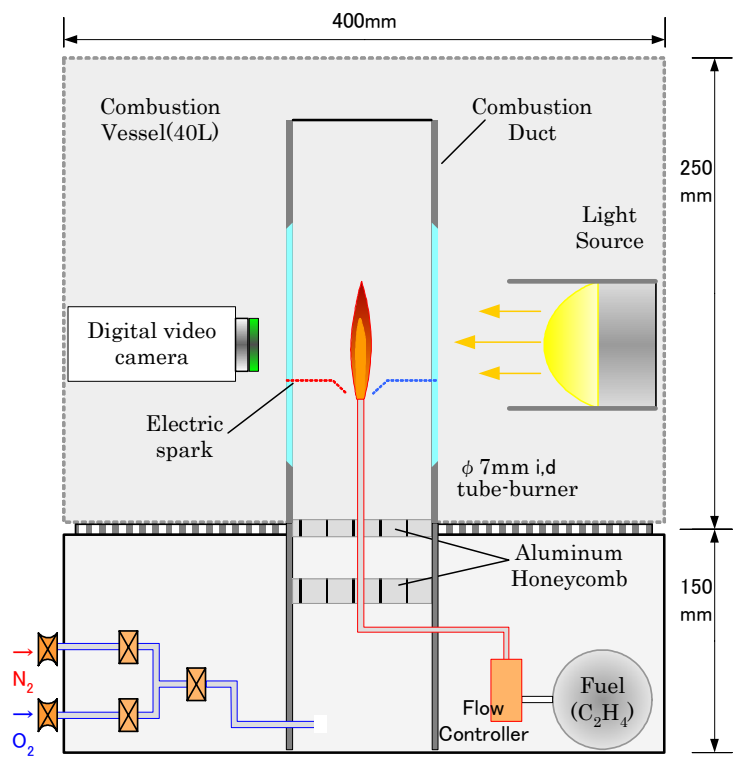

Fig.1 Schematic description of experimental setup

The setup is enclosed in a 40 liter closed cubic vessel with other controlling apparatus. A video camera is used to take both direct and shadow images with backlight. Pure ethylene as a fuel is supplied at a constant flow rate to the tubular stainless burner with inner and outer diameters of 7 and $8 \mathrm{~mm}$, respectively. The corner of the burner rim is ground to reduce the rim thickness at the burner exit, which helps to avoid the disturbance at the downstream of the rim. The fuel is injected into a combustion duct and ignited by electric spark. The combustion duct has a square cross section of $50 \times 50 \mathrm{~mm}$ and length of $250 \mathrm{~mm}$. Combustion air of desirable composition charged in the gas cylinder is supplied from the 
bottom of the duct at a constant flow rate. Since the enclosure vessel allows combustion gas to leak out, constant pressure is maintained.

Fuel flow rates set in the experiments were $2.0 \mathrm{~mL} / \mathrm{sec}$ (mean injection velocity $5.1 \mathrm{~cm} / \mathrm{s}$ ) and $2.4 \mathrm{~mL} / \mathrm{sec}(6.23 \mathrm{~cm} / \mathrm{s})$ and air flow velocity (flow rate is divided by cross section area assuming uniform flow distribution) around the tubular burner was changed from 2.5 to $7.3 \mathrm{~cm} / \mathrm{sec}$. Oxygen concentration in the combustion air was 21 or $23 \%$ (in volumetric value) balanced with nitrogen. To obtain uniform flow field in the duct, combustion air was supplied through double-aluminum honeycomb structure, i.e. two pieces of 750cells per square inch honeycomb. All the experiments were carried out at room temperature and atmospheric pressure. Flow rate of fuel and surrounding air were adjusted by using flow controllers, which were calibrated by soap bubble flow meter for the fuel flow rate and volumetric flow meter for the air flow. The error of flow controller for fuel and air was $\pm 2 \%$. In the test sequence supply of fuel and air started with opening electrically controlled solenoid valve at first. Then spark igniter and backlight were turned on immediately. Once ignition occurred, electric spark was stopped. These sequences must be automatically controlled only with one start signal, because microgravity experiments do not allow access to the capsule inside right before drop. Figure 2 shows sequential chart for experimental setup operation. Drop test is carried out only when stable flame is confirmed after ignition.

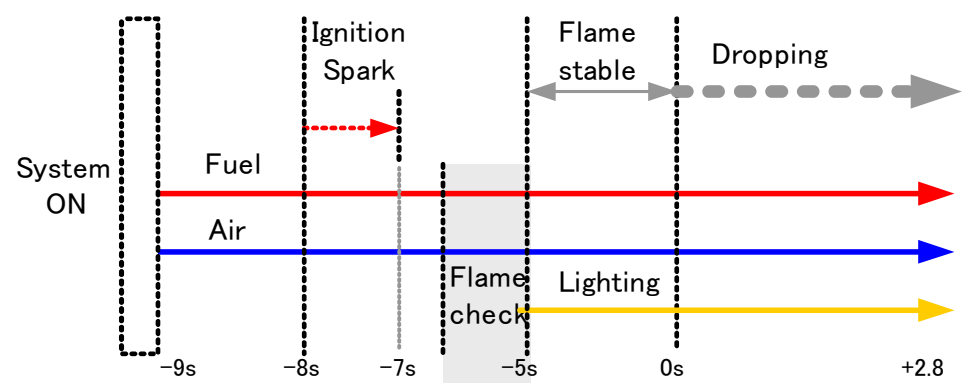

Fig.2 Sequence diagram

Backlight images were taken by video camera and attenuation ratio to the original backlight brightness was determined two-dimensionally. Bouguer-Lambert-Beer formula is used for evaluating light extinction phenomena and can be expressed as Eq. (2.1)

$$
-\ln \frac{I}{I_{0}}=Q_{\text {ext }} \frac{\pi}{4} D^{2} N L
$$

$$
\begin{aligned}
& \mathrm{I}_{0} \quad \text { : Initial light intensity } \\
& \text { I : Transmitted light intensity } \\
& \text { D : Particle diameter } \\
& \mathrm{N} \text { : Number density } \\
& \text { L : Optical path length } \\
& \mathrm{Q}_{\text {ext }} \text { : Attenuation coefficient }
\end{aligned}
$$

Equation (2.1) is applicable to the soot particle aggregate in the flame. Coefficient of light extinction $\mathrm{Q}_{\text {ext }}$ can be expressed as the sum of $\mathrm{Q}_{\text {abs }}$ and $\mathrm{Q}_{\text {sca, }}$, which represent coefficients of absorption and scattering, respectively (Eq. (2.2)).

$$
\mathrm{Q}_{\mathrm{ext}}=\mathrm{Q}_{\mathrm{abs}}+\mathrm{Q}_{\mathrm{sca}}
$$

where $\mathrm{Q}_{\mathrm{abs}}$ is coefficient of absorption and $\mathrm{Q}_{\text {sca }}$ is coefficient of scattering. Light extinction 
of soot aggregate by scattering is negligible in comparison with the light extinction by absorption. Thus, $\mathrm{Q}_{\text {ext }}$ is assumed to be $\mathrm{Q}_{\mathrm{abs}}$. The coefficient of absorption by particles can be expressed as follows from the formula of Rayleigh's Law, where $\lambda$ is wavelength of selected light wavelength $\left(\mathrm{Q}_{\mathrm{abs}}\right)$.

$$
Q_{a b s}=12 \frac{\pi D}{\lambda} \frac{2 n k}{\left(n^{2}+k^{2}\right)+4\left\{1+\left(n^{2}-k^{2}\right)\right\}}
$$

For soot particle, $\mathrm{n}=1.56$ and $\mathrm{k}=0.5$ from empirical data [18]. Then the concentration of density of soot is written as below.

$$
C_{s}=-\frac{2}{3} \frac{\rho_{s} D}{L Q_{a b s}} \ln \left(\frac{I}{I_{0}}\right) \quad(\mathrm{g} / \mathrm{mm} 3)
$$

$\rho_{\mathrm{s}}$ : Density of soot particle

$\mathrm{C}_{\mathrm{s}}$ : Concentration of soot particle

Partial volume fraction of soot is $F_{v}=C_{s} \times \frac{1}{\rho_{s}}$,

and can be re-written as Eq. (2.5) [18,19] from Eq. (2.4).

$$
F_{v}=\frac{2}{3 \times 2.95} \frac{\lambda}{L}\left(-\ln \frac{I}{I_{0}}\right)\left(\mathrm{mm}^{3} / \mathrm{mm}^{3}\right)
$$

From Eq. (2.5), soot volume fraction in the flame can be calculated by obtaining incident light intensity, $\mathrm{I}_{0}$, intensity of extinction light, $\mathrm{I}$, and physical length of extinction, $\mathrm{L}$. The selected wavelength of the incident light $(\lambda)$ is designated by the band pass filter described below. An interference filter (546nm center, $10 \mathrm{~nm}$ band width for half value) was used to select the wavelength for extinction image and also to eliminate light emission from the luminous flame.

Since the attenuation measurement of backlight is a kind of in-line method, two-dimensional image should be reconstructed into concentric distribution by Abel-transformation method assuming axis-symmetric distribution.

The drop tower used in the test has a height of about $50 \mathrm{~m}$ to provide $2.5 \mathrm{sec}$ free fall duration. Microgravity level is around $1 \times 10^{-3} \mathrm{G}$ attained by double capsule system and impact of the breaking is around $17 \mathrm{G}$. Therefore, the setup should be durable for that instantaneous large gravity level. Before capsule drop flame shows well-known flame shape controlled by buoyancy. When the capsule is released, flame shape changes into a unique one in microgravity. To obtain data, we found out the time needed to stabilize the flame based on the soot concentration variation with respect to the time. The response time to reach steady state of the flame in microgravity depends on the external flow velocity. It takes around $1.3 \mathrm{sec}$ or less for $2.5 \mathrm{~cm} / \mathrm{s}$ of co-axial flow and less than that for the case of higher flow velocity. In the present paper, therefore, the data at $1.6 \mathrm{sec}$ after the drop are used for the discussion in the later chapter assuming the flame reaches steady state at the moment.

\section{Results and Discussion}

Figure 3 showed the direct pictures of the flame with different co-flow velocity under microgravity. Flame image was taken by a video camera at shutter speed of 1/725 second and aperture value of F4.

The visible flame width decreases and flame brightness increases with increase in co-axial flow velocity. Further, the brightness change of the flame edge is evident implying the increased temperature at the flame zone. The radial edge of flame becomes clearer with 
increased co-axial flow implying narrower flame zone of diffusion flame, while the boundary of flame edge at the tip of flame is not clear even with maximum flow velocity in the figure. The similar unclear boundary can be seen in earlier observation of non-buoyant round laminar jet diffusion flames in microgravity [3,4,21-24]. These flames are free from flickering phenomenon, a unique instability of buoyant laminar jet diffusion flames in normal gravity.

As the flames in $1 \mathrm{G}$ with the same fuel flow rate always show closed conical tip, the effect of microgravity appears evidently at the tip of the flame. In the Fig.3 flame tip-opening phenomenon is always found for all tested external flow condition. Flame is quenched near its tip due to insufficient oxygen supply into the flame and continuum radiation heat losses from the formed soot.

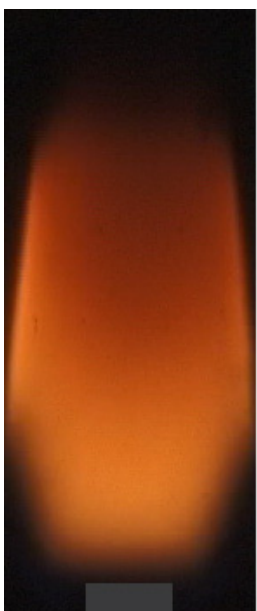

$2.5 \mathrm{~cm} / \mathrm{s}$

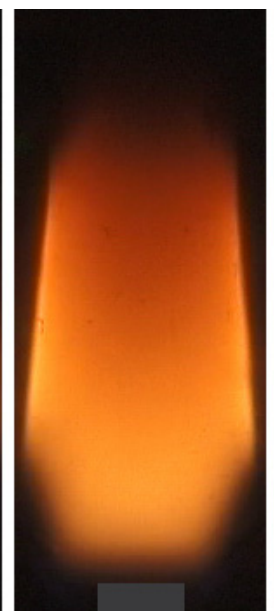

$3.7 \mathrm{~cm} / \mathrm{s}$

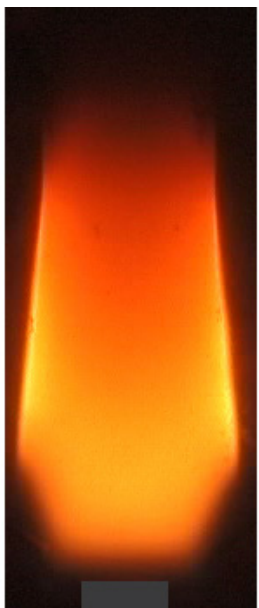

$5 \mathrm{~cm} / \mathrm{s}$

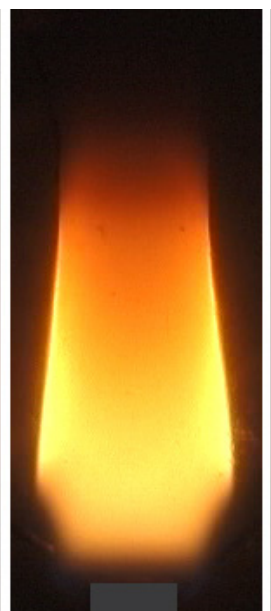

$6.2 \mathrm{~cm} / \mathrm{s}$

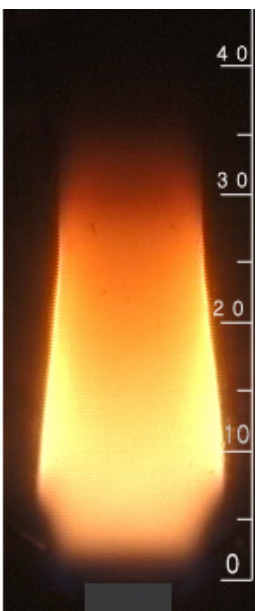

$7.3 \mathrm{~cm} / \mathrm{s}$

Fig.3 Flame images at various co-axial flow velocities $\left(\mathrm{Q}_{\mathrm{f}}=2.0 \mathrm{~mL} / \mathrm{s}, \mathrm{O}_{2}=23 \%\right.$, Burner $\left.\phi 7 \mathrm{~mm}\right)$

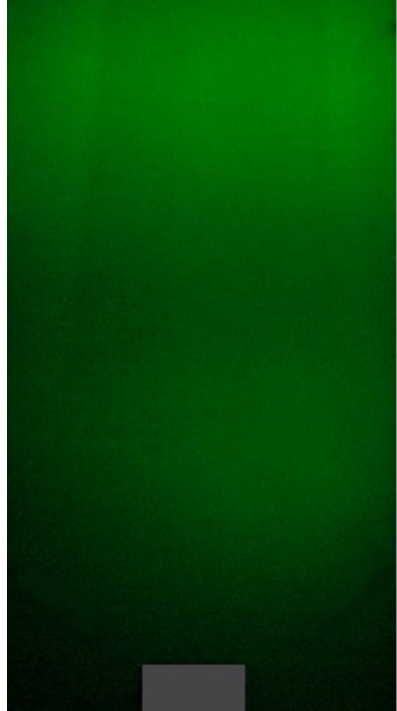

$2.5 \mathrm{~cm} / \mathrm{s}$

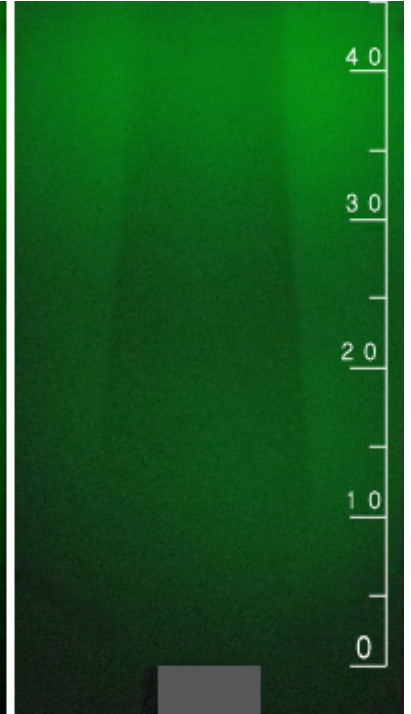

$7.3 \mathrm{~cm} / \mathrm{s}$

Fig.4 Comparison of backlight images with different co-axial flow velocity $\left(\mathrm{Q}_{\mathrm{f}}=2.0 \mathrm{~mL} / \mathrm{s} \mathrm{O}_{2}=23 \%\right.$, Burner $\left.\phi 7 \mathrm{~mm}\right)$

Figure 4 shows backlight images at $U a($ co-axial flow velocity $)=2.5 \mathrm{~cm} / \mathrm{s}$ and $U a=7.3 \mathrm{~cm} / \mathrm{s}$. The shadow of the flame caused by the presence of soot is clearer at larger flow velocity, 
which suggests that soot concentration increases with external flow velocity. When the external flow velocity is extremely high, the amount of soot concentration does not always increase with external flow velocity, while soot concentration in low external flow velocity region increases with the flow velocity.

To discuss the soot formation characteristics in detail, radial distribution of soot was calculated at $30 \mathrm{~mm}$ high above the burner exit. The reason to select the height of $30 \mathrm{~mm}$ for the comparison is that the difference of soot concentration is the most evident in Fig. 6 showing soot distribution along the flame height.

Figure 5 shows an example of the radial soot distribution at the condition of $\mathrm{Q}_{\mathrm{f}}=2.0$ $\mathrm{mL} / \mathrm{s}$ and $23 \%$ oxygen concentration. In the figure soot concentration at each radial position is shown after the calculation of Able-transformation. It is easily understood that the soot concentration is quite high near the edge of the flame, while it is low near the center of the flame at this height. At any radial position, the soot concentration becomes higher with higher external flow velocity, suggesting the increasing trend of soot formation.

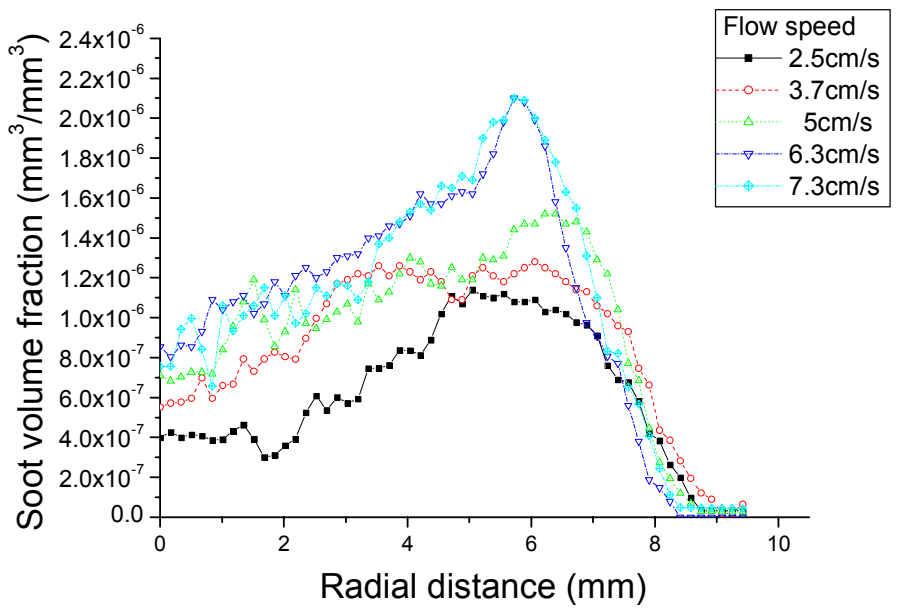

Fig5. Radial distribution of soot volume fraction after the Abel-transformation $\left(\mathrm{H}=30 \mathrm{~mm}, \mathrm{Q}_{\mathrm{f}}=2.0 \mathrm{~mL} / \mathrm{s}, \mathrm{O}_{2}=23 \%\right)$

To better understand the effect of co-axial flow on soot formation characteristics, Fig.6 demonstrates the trend of soot concentration change along the distance from the burner exit with different external flow velocities. The value plotted in the figure is the mean soot volume fraction at every $5 \mathrm{~mm}$ height of the flame based on the radial distribution obtained at each height as given in Fig.5.

As a general trend of the soot distribution characteristics, it is understood that soot concentration increases with an increase in the axial distance at the lower position of the flame and then it peaks out at a given height. The decrease trend of mean soot volume fraction after the peak value implies the soot oxidation effect in the downstream region. One of the important facts in the figure is the difference of soot concentration with different co-axial flow velocity, that is, the higher co-axial flow velocity, the higher soot concentration at every height. Generally, soot concentration at the upstream region of the flame is strongly affected by the rate of soot formation reaction. The difference shown in Fig. 6 is more evident at the upstream region, which implies that soot formation rate increases with an increase in the co-axial flow velocity within the range tested in the present work. 


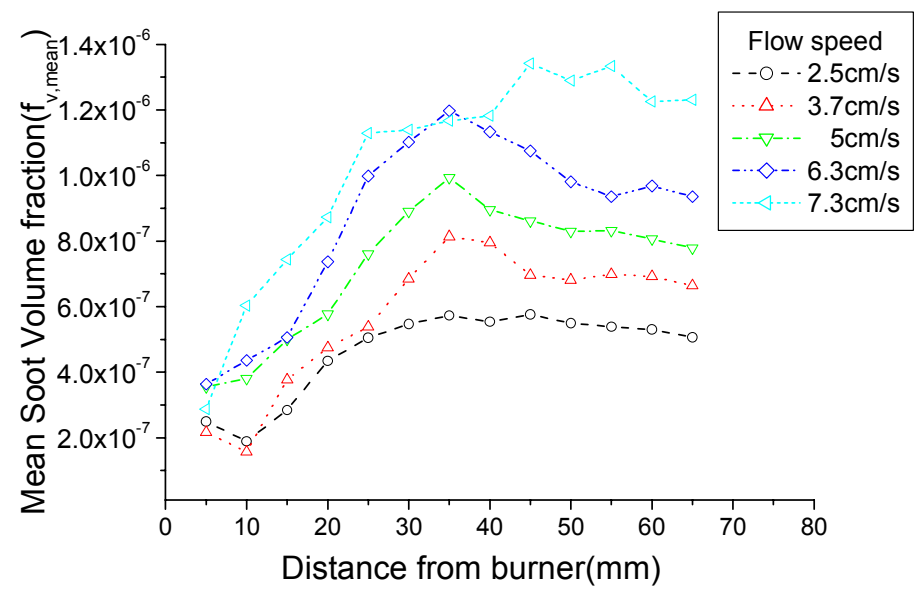

Fig.6 Mean soot volume fraction of every height from the burner exit $\left(\mathrm{Q}_{\mathrm{f}}=2.0 \mathrm{~mL} / \mathrm{s}, \mathrm{O}_{2}=23 \%, \mathrm{Ua}=2.5-7.3 \mathrm{~cm} / \mathrm{s}\right)$

Figure 7 shows a total soot volume within the area of photograph taken in the experiments (for example, see Fig.3) as a function of co-axial flow velocity. In the figure fuel supply rate and oxygen concentration are changed as experimental parameters. According to the figure, it is clear that the total soot volume increases with increase in external flow velocity. Especially the difference between the soot volumes at $\mathrm{Ua}=2.3$ and $3.7 \mathrm{~cm} / \mathrm{s}$ is fairly large, while the change with co-axial flow velocity is relatively mild at higher velocity than $3.7 \mathrm{~cm} / \mathrm{s}$. In the figure the importance of oxygen concentration and fuel flow rate on soot formation is also indicated. When oxygen concentration is fixed, soot formation amount is always larger with larger fuel supply rate. Similarly, total soot volume is always larger with higher oxygen concentration when fuel flow rate is fixed. It is interesting to note that the total soot volume at $\mathrm{Q}_{\mathrm{f}}=2.0 \mathrm{~mL} / \mathrm{s}$ and $\mathrm{O}_{2}=23 \%$ evidently exceed that at $\mathrm{Q}_{\mathrm{f}}=2.4 \mathrm{~mL} / \mathrm{s}$ and $\mathrm{O}_{2}=21 \%$. This fact suggests that the effect of increased oxygen is quite important for the soot formation in this flow rate range. In the flame within very low external flow flame temperature tends to be low as a characteristic of diffusion flame including the effect of radiation heat loss. Therefore, higher oxygen is more effective to increase soot formation through increased flame temperature. The effect of external flow velocity could also be explained based on the effect temperature increase.

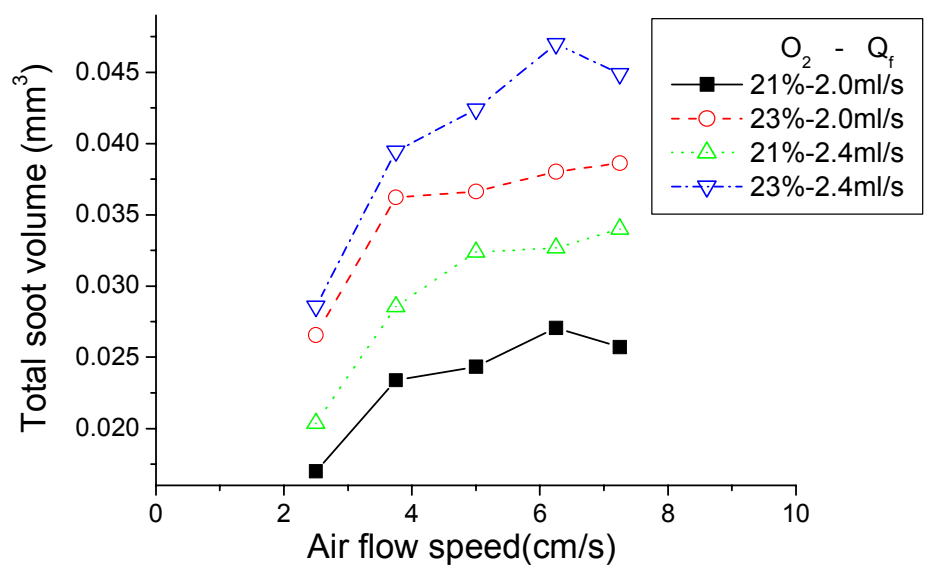

Fig.7 Total soot volume change with various co-axial flow velocities 


\section{Comparison with Numerical Calculation}

To discuss the difference of flame structures depending on the co-axial flow velocity, distribution of temperature and chemical species were numerically estimated by using Fire Dynamic Simulator (FDS) provided by NIST [25] for the experimental conditions of this research. In the calculation, the finite-rate reactions were assumed as chemical reaction and the one-step chemical reaction was used for ethylene. The direct numerical simulation (DNS) was selected for the calculation with applying viscosity of $9.1 \mathrm{~kg} / \mathrm{m} / \mathrm{s}$, thermal conductivity of $0.0205 \mathrm{~W} / \mathrm{m} / \mathrm{K}$ and diffusion coefficient of $1.17 \times 10^{-5} \mathrm{~m}^{2} / \mathrm{s}$. Wall temperature was set as $300 \mathrm{~K}$ and radiation transport was not considered in the calculation.

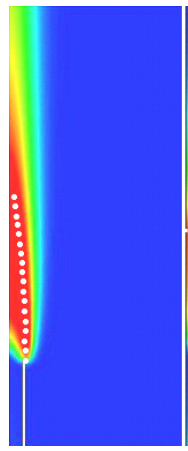

$1 \mathrm{G} 0 \mathrm{~cm} / \mathrm{s}$

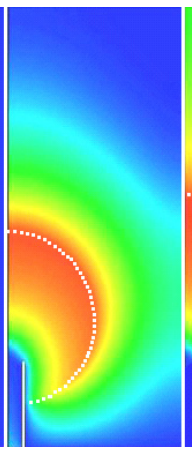

$0 \mathrm{~cm} / \mathrm{s}$

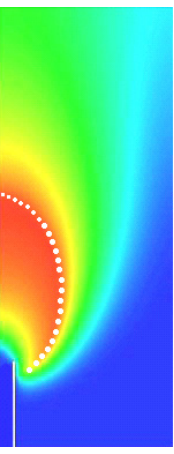

$2.5 \mathrm{~cm} / \mathrm{s}$

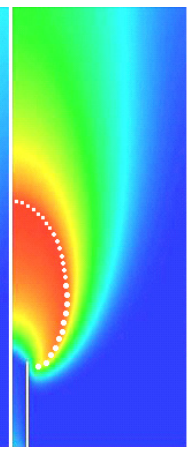

$3.7 \mathrm{~cm} / \mathrm{s}$

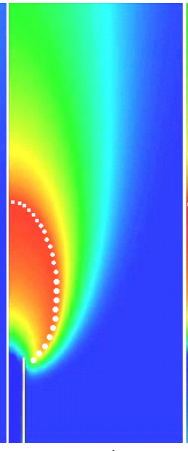

$5 \mathrm{~cm} / \mathrm{s}$

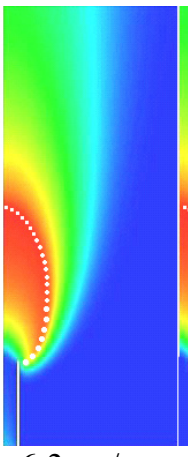

$6.3 \mathrm{~cm} / \mathrm{s}$

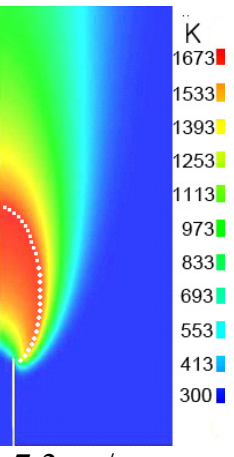

$7.3 \mathrm{~cm} / \mathrm{s}$

Fig.8 Distribution of flame temperature for different co-axial flow velocities (K)

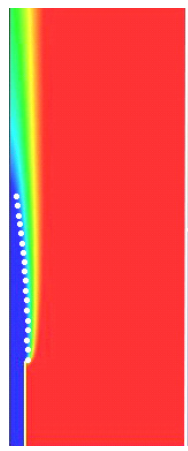

$1 \mathrm{G} 0 \mathrm{~cm} / \mathrm{s}$

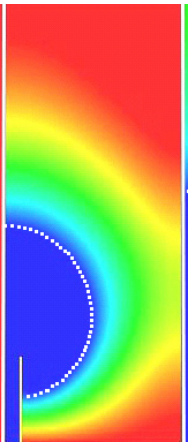

$0 \mathrm{~cm} / \mathrm{s}$

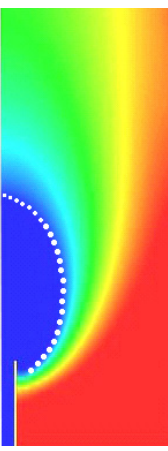

$2.5 \mathrm{~cm} / \mathrm{s}$

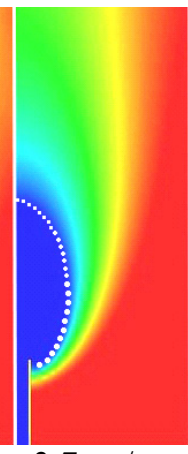

$3.7 \mathrm{~cm} / \mathrm{s}$

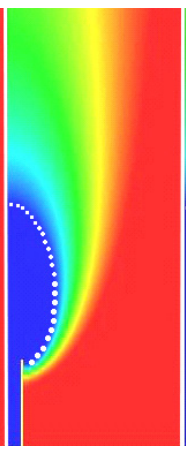

$5 \mathrm{~cm} / \mathrm{s}$

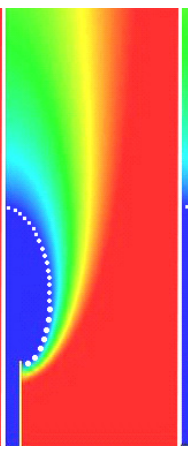

$6.3 \mathrm{~cm} / \mathrm{s}$

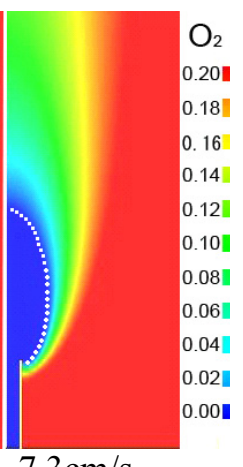

$7.3 \mathrm{~cm} / \mathrm{s}$

Fig.9 Distribution of oxygen mass fraction for different co-axial flow velocities $(\mathrm{kg} / \mathrm{kg})$

Figures 8 and 9 show the change of temperature and oxygen concentration distribution (at $\mathrm{O}_{2}=21 \%, \mathrm{Q}_{\mathrm{f}}=2.0 \mathrm{~mL} / \mathrm{s}$ ) obtained from the numerical calculation, respectively. In the figures the position of maximum heat release rate is indicated by dashed line. In these figures, the calculated result for $1 \mathrm{G}$ is also included. The maximum flame temperature at $1 \mathrm{G}$ reaches up to around $2100 \mathrm{~K}$, while it becomes around $1700 \mathrm{~K}$ for other cases corresponding to microgravity condition ( $400 \mathrm{~K}$ less than $1 \mathrm{G}$ case). When comparison is made among low external flow cases under microgravity, it is understood that the maximum flame temperature tends to increase with increase in co-axial flow velocity. Further the temperature distribution becomes narrower with higher flow velocity.

Figure 9 shows the oxygen concentration distribution (note the value is given by mass fraction here) with the maximum heat release line described by the dashed line. In the interior of flame within the dashed line, oxygen scarcely exists due to insufficient oxygen diffusion and excess reducing agents (mainly fuel itself) remain in the region. When Figs. 8 and 9 are superposed, it is understood that the high temperature region distributes towards 
both side of maximum heat release line and inside of the dashed line, where high concentration of reducing agents remains without oxygen, is exposed to high temperature condition. According to the previous researches [26,27] by other researchers it has been known that the relative position of temperature field and chemical composition distributions determine the soot formation characteristics. Namely when potential soot formation region in chemical view is exposed to high temperature condition, a large amount of soot is produced. As seen in Fig. 8 the maximum flame temperature increases with increase in co-axial flow velocity and the increase of the temperature causes higher temperature of the fuel excess region of the flame. This change with the co-axial flow causes the increasing trend of soot concentration at a given radial position of the flame as seen in Fig.5 and the resulting trend of total soot volume as seen in Fig.7.

Figure 10 shows the maximum temperature change of the flame for $\mathrm{Q}_{\mathrm{f}}=2.0 \mathrm{~mL} / \mathrm{s}$ with different $\mathrm{O}_{2}$ conditions, $\mathrm{O}_{2}=21 \%$ and $23 \%$. As seen in the figure the absolute value of estimated temperature at $\mathrm{O}_{2}=21 \%$ is around $1680 \mathrm{~K}$, while it reaches around $2100 \mathrm{~K}$ in $1 \mathrm{G}$ (see Fig.8). Therefore, the relatively low temperature in low flow velocity condition may limit the soot formation. In the calculation, as the radiation heat loss is not included the actual temperature increase with increase in air flow velocity must be more evident than the trend in Fig.10. As a result, total soot volume in Fig.7 tends to increase monotonically corresponding to the increase of flame temperature with increased external air flow velocity.

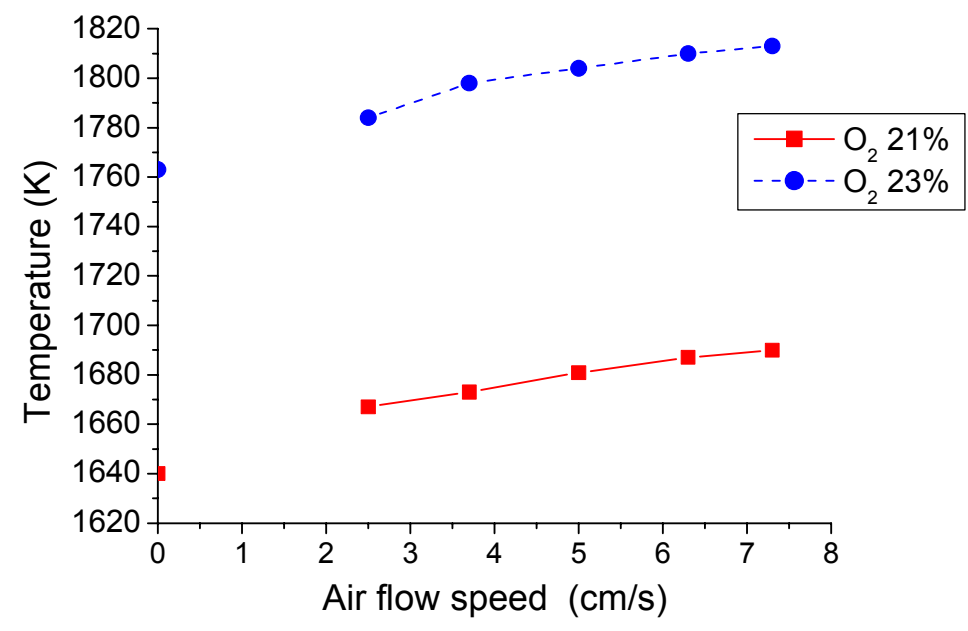

Figure 10 Maximum flame temperatures in the flame as a function of co-axial flow velocity estimated by numerical calculation code, FDS.

\section{Conclusions}

The effect of co-axial flow on soot formation in a laminar jet diffusion flame has been investigated in microgravity. The tested co-axial flow velocity range is very low, $0-7.3 \mathrm{~cm} / \mathrm{s}$, which is difficult to set on the ground because of the presence of buoyancy induced disturbance. The results of the study may be summarized as follows.

(1) The dependency of soot formation on the very low external flow is firstly obtained by utilizing microgravity environment. Soot concentration monotonically increases with increase in the external flow velocity within the tested range.

(2) According to the radial distribution, the effect of co-axial flow velocity evidently appears near the visible flame edge rather than the center of the flame. On the other hand, in the axial distribution soot concentration increases with axial distance from the burner rim and then peaks out at a given height, while the decrease of soot concentration after the peak 
is not so evident.

(3) A comparison with numerical calculation suggests that the increase of soot concentration is caused by increased flame temperature in the area of low oxygen and fuel excess region. As the flame in a very low external flow has much lower flame temperature than that of flame surrounded by buoyancy induced flow in $1 \mathrm{G}$, the increase in flame temperature with increased co-axial flow causes increase of total soot formation in the flame.

\section{References}

(1) Law, C.K. and Faith, G.M. Prog. Energy Combust. Sci. Vol. 20, (1994) 65-116

(2) Kaplan, C.R. Oran, E.S., Kailasanath, K. Proceedings of the Combustion Institute (1996), Vol.26, 1301-1309

(3) Bahadori,M.Y., Edelman,R.B.,. Sotos,R.G., and Stocker,D.P., AIAA paper 91-0791,Jan 1991

(4) Bahadori,M.Y., Edelman,R.B., Stocker,D.P., and Olson,S.L., AIAA Journal Vol. 28,No2,1990 236-244

(5) Sunderland P.B, and Faeth,G.M., 2nd Int. Microgravity Combustion Symposium 351-356 (1996)

(6) Law, C.K. and Faeth,G,M. Process in Energy and Combustion Science, Vol. 20, No1,1994 pp65-113

(7) Lin, K.C, Faeth, G.M., Sunderland, P.B. Combust. Flame 116:415-431(1999)

(8) Lin, K.C, and Faith,G.M., AIAA J, Vol37, pp759-765, (1999)

(9) Lin, K.C, Faeth, G.M. Sunderland P. B, Urban D. L, Yuan Z.-G, Combustion and Flame (1999), 116(3) 415-431

(10) Lin, K.C., Sunderland, P. B., Faeth, G.M. Combustion and Flame (1996), 104(3), 369-375

(11) Xu,F., Dai,Z., Faeth, G.M., AIAA J,2002 vol.40(12),2439-2446

(12) Dai, Z., Faeth,G.M., Proceedings of the Combustion Institute, Vol. 28.(2000). 2085-2092

(13) Sunderland,P.B., Koylu,U.O., and Faeth G.M., Combustion and Flame Vol. 100 No1/2 1994 97-103

(14) Lin,K,C. Sunderland P,B, and Faeth,G.M. Combustion and Flame Vol. 104 No3 1996 369-375

(15) Walsh,K.T., Joseph, F., Smooke, M.D., Long, M.B. Proceedings of the Combustion Institute (2000), 28(2), 1973-1979

(16) Kono,M., Ito,K., Niioka,T., Kaota,T, and Sato,J., Proceedings of the Combustion Institute (1996), Vol.26,1117-1126

(17) Fujita,O., Ito,H., Nakamura,Y., Uematsu,T., and Ito,K., Microgravity combustion research by utilizing the new 50M drop tower, IAC-05-A2.7.02, CD-ROM, $(2005,10)$

(18) Dalzell.W.H., and Sorofim, A.F., Trans. ASME Heater Transfer 91:100-104(1969)

(19) Kamimoto, T, nainenkikan, J.P., vol.25 (314), 27-34,(1986)

(20) Kamimoto, T, nainenkikan, J.P., vol.25 (315), 93-99,(1986)

(21) Cochran,T.H., and Masica,W.J.,. Proceedings of the Combustion Institute (1970), Vol.13, 821-829

(22) Haggard ,J.B., Jr, and Cochran,T.H., Combustion science and technology Vol5,No4-6 1972 291-298

(23) Edelman,R.B., and Bahadori,M.Y,. Acta Astronautica, Vol.13, No11/12 1986 681-688

(24) Fujita,O., Ito,K., Experimental Thermal and Fluid Science. 26 (2002) 305-311

(25) NIST http://fire.nist.gov/fds/

(26) Gulder, O.L., and Snelling, D.R., Combust. and Flame 92:(1993) 115-124

(27) Santoro, R.J., et al., Combust. Sci. Tech. 53:2-3(1987) 89-115 